\title{
Evaluation of effect of vitamin D supplementation on vitamin D levels and pregnancy outcome
}

\author{
Shaifali Patil ${ }^{1}$, Shivali Tripathi ${ }^{2 *}$, Siddharth $\mathrm{Shah}^{3}$ \\ ${ }^{\mathbf{1}}$ Associate Professor, ${ }^{\mathbf{2}, 3}$ Junior Resident-III, Dept. of Obstetrics and Gynecology, MGM Medical College, Kalamboli, Navi \\ Mumbai, Maharashtra, India \\ *Corresponding Author: \\ Email: researchexpert3@gmail.com
}

Received: $17^{\text {th }}$ February, 2018

Accepted: $31^{\text {st }}$ March, 2018

\begin{abstract}
Introduction: Vitamin D is a fat-soluble vitamin which comes primarily from exposure to sunlight, and only few foods acts as a source of it. Vitamin D deficiency is a preventable health problem. Research shows that during pregnancy, adequate vitamin D intake is necessary for maternal, fetal and child health. This study was conducted to determine prevalence of vitamin D deficiency in pregnant women and neonates and will also help us to determine if 400IU daily recommended dose is sufficient to treat hypovitaminosis D.

Materials and Methods: The study was carried out for $1 \frac{1 / 2}{2}$ years on 100 pregnant, divided in two groups in which one group was given supplementation and 2nd group was of unregistered patients.

Results: The prevalence of Vitamin D deficiency was observed as $82 \%$ in present study. On supplementing the subjects with $400 \mathrm{IU}$ vitamin D with calcium $1000 \mathrm{mg}$ daily, the prevalence reduced to $14 \%$ while normal levels were achieved in $58 \%$ as compared to $8 \%$ during the first trim which was significant with $\mathrm{p}$ value of $<0.01$.

Conclusion: We recommend evaluation of the status of vitamin D in all pregnant women along with D3 supplementation. Routine supplementation of pregnant mothers with 400IU vitamin D with calcium $1000 \mathrm{mg}$ daily resulted in significant improvement of vitamin D levels in study group, but sufficient levels were reached in just over half of the females. We thus propose further research on the daily dosage recommendations along with other factors affecting vitamin D levels in pregnant females like eating pattern, compliance to prescribed drugs and sun light exposure.
\end{abstract}

Keywords: Vitamin D levels, Vitamin D deficiency in pregnancy.

\section{Introduction}

Vitamin D is a fat-soluble vitamin which primarily can be obtained on exposure to sunlight. It is also found naturally in fish-liver oils, fatty fish, mushrooms, egg yolks, and liver etc. Vitamin D (calciferol) is active in two forms: D2 and D3. Vitamin D2 (ergocalciferol) is synthesized by plants and vitamin D3 (cholecalciferol) is produced in humans from 7-dihydroxycholecalciferol after exposure to ultraviolet light B (UVB) radiation. ${ }^{1}$ Both D2 and D3 forms has a similar metabolism and is available in vitamin $\mathrm{D}$ supplimentation in both formats. Under influence of parathyroid hormone, cholecanciferol is first hydroxylated in the liver to form calcidiol and then in the kidney to calcitriol. ${ }^{2,3}$ Calcitriol is an important pre-hormone which is involved in metabolic processes including bone integrity and calcium homeostasis. ${ }^{4}$ Vitamin D deficiency can be prevented. Vitamin D deficiency among pregnant women is public health concern in many parts of the world. Many studies have concluded that during pregnancy, adequate intake of vitamin $\mathrm{D}$ is necessary for achieving optimal maternal, fetal and child health. Complications associated with vitamin D deficiency during pregnancy are preeclampsia; gestational diabetes mellitus and cesarean section. Whereas those in newborns are low birth weight, neonatal rickets etc. Vitamin D is also associated with neurodevelopment and development of immune system during the pregnancy itself. Therefore, prevention of vitamin D deficiency during pregnancy is of utmost importance. According to some studies, the currently recommended vitamin D supplement schedule is not sufficient to maintain the desirable value of vitamin D during pregnancy. ${ }^{5}$

This study was conducted to determine the prevalence of hypovitaminosis D in mothers and fetuses, to study complications due to hypovitaminosis $\mathrm{D}$ and to establish recommended daily doses of vitamin D in pregnant women.

\section{Materials and Methods}

The study was carried out among $100 \quad$ (50 registered in the first trimester and 50 visiting for the first time in labor) at MGM Medical College, Kalamboli, Navi Mumbai. The study was conducted for the period of 1.5 years. Patients fitting into the inclusion criteria were selected for the study. Written informed valid consent were taken from all patients. Detailed history taking and examination were done.

Methods: Patients were divided into 2 groups as follows:

Group A: Patients visiting OPD for the first visit in her first trimester (1 -12 weeks) were enrolled. The patient was supplemented with $400 \mathrm{IU}$ vitamin D with calcium 1000mgdaily after 1 st trimester (from 14 weeks until 
delivery). In these patients, 3 sample was taken to measure vitamin D3 levels.

1. 1st sample was taken on patient's first antenatal visit

2. The 2nd sample was taken when the patient is in labor

3. The 3rd sample was of cord blood for determining neonatal vitamin D3 level.

Group B: Patients visiting Hospital for the first time in labor. In these patients 2 samples were taken to measure vitamin D3 levels 1st sample was taken when the patient is in labor \& 2nd sample was of cord blood for determining neonatal vitamin D3 level. Venous blood was collected from study group under all aseptic condition and was analyzed for serum vitamin D on fully automated chemiluminescence analyzer.

Pregnant women with metabolic or systemic illness, Patients already on vitamin D supplementation or defaulters I.e. patients who did not take regular supplementations or who did not come for delivery at our center or were with poor follow up were excluded from the study.

\section{Results}

A total of 100 subjects were divided into 2 groups. Group A: patients visiting OPD for the first visit in her first trimester (1-12 weeks) supplemented with 400IU vitamin D with calcium $1000 \mathrm{mg}$ daily; and Group B: Patients visiting Hospital for the first time in labor. Mean age of the study subjects was comparable in groups A and B respectively (26.08 years vs 25.08 years; p-0.185) (Table 1).

The prevalence of vitamin D deficiency was observed as $82 \%$ in the present study. On supplementing the subjects with $400 \mathrm{IU}$ vitamin D with calcium $1000 \mathrm{mg}$ daily, the prevalence reduced to $14 \%$ while normal levels were achieved in 58\% as compared to $8 \%$ during the first term which was significant with a p-value of $<0.01$ (Table 2). The females who directly reported during labor (Group B) had vitamin D deficiency (78\%) as compared to vitamin supplemented Group A (14\%). Sufficient levels were present in only $4 \%$ in group B as compared to $58 \%$ in group A with a p-value of $<0.01$ (Table 3). Vitamin D deficiency in cord blood was present in $74 \%$ of Group B subjects as compared to $22 \%$ in group A while sufficient levels were seen in only $10 \%$ in group B compared to $50 \%$ in group A subjects. Vitamin D deficiency in cord blood was significant in Group B neonates with a p-value of $<0.01$ (Table 4). Mean D3 Levels at labor and cord blood levels were significantly ( $\mathrm{P}$ value $<0.01$ ) more in D3 supplemented group A as compared to group B (31.35 vs 12.53 and 29.51 vs 13.88 ) with a p-value of $<0.01$ for both (Table $3 \& 4$ ). Mean birth weight was higher in D3 supplemented group A as compared to group $\mathrm{B}(2.81 \mathrm{Kg}$ vs $2.74 \mathrm{~kg})$, but the difference was non-significant (P-value 0.335). Birth weight of $<2.5$ $\mathrm{Kg}$ was seen in only $3 \%$ babies born to vitamin $\mathrm{D}$ sufficient mothers as compared to $19 \%$ and $26.1 \%$ in mothers with insufficient and deficient levels. Which shows that low birth weight was common in vitamin D insufficient and deficient patients with a p-value of $<0.05$ (Table 5). Pre-eclampsia was seen in $16 \%$ cases in group $\mathrm{B}$ as compared to $8 \%$ in group $\mathrm{A}$, but the difference was not significant ( $\mathrm{P}$ value of 0.36 ). Other complications like GDM and IUFD was comparable between the two groups (with a p-value of $>0.05$ ) (Fig. 1). Group A had 58\% normal deliveries as compared to Group B in which $66 \%$ had normal deliveries. Group A had $42 \%$ LSCS rate as compared to $34 \%$ in Group B (Fig. 2). There was no significant difference observed in the rate of Caesarean section among group $\mathrm{A}$ and $\mathrm{B}$ (with a $\mathrm{P}$ value of 0.54 ). In all 100 patients, there was no significant difference observed in the rate of Caesarean section among vitamin $\mathrm{D}$ deficient, insufficient and sufficient mothers $(37 \%$ vs $33.3 \%$ vs $42.4 \%$ ) with a p-value of 0.78 (Table 6).

Table 1. Comparison of mean age among study groups

\begin{tabular}{|c|c|c|c|c|c|}
\hline Variables & Group & Mean & SD & SEM & P-value \\
\hline \multirow{2}{*}{ Age in years } & A & 26.08 & 3.82 & 0.54 & \multirow{2}{*}{0.185} \\
\cline { 2 - 5 } & $\mathrm{B}$ & 25.18 & 2.86 & 0.40 & \\
\hline
\end{tabular}

Table 2. Comparison of D3 levels at 1st term and labour in Group A

\begin{tabular}{|l|c|c|}
\hline \multirow{2}{*}{\multicolumn{1}{|c|}{ D3 Level }} & \multicolumn{2}{c|}{ Group A } \\
\cline { 2 - 3 } & $\mathbf{1}^{\text {st }}$ term & Labour \\
\hline Deficiency & $41(82.0 \%)$ & $7(14.0 \%)$ \\
\hline Insufficiency & $5(10 \%)$ & $14(28 \%)$ \\
\hline Sufficiency & $4(8 \%)$ & $29(58 \%)$ \\
\hline Total & $50(100 \%)$ & $50(100 \%)$ \\
\hline P-value & \multicolumn{2}{|c|}{$<0.01$} \\
\hline
\end{tabular}


Table 3. Comparison of D3 levels at labour among study groups

\begin{tabular}{|l|c|c|c|c|}
\hline \multirow{2}{*}{ D3 level at labour } & \multicolumn{2}{|c|}{ Group } & \multirow{2}{*}{ Total } & \multirow{2}{*}{ P-value } \\
\cline { 2 - 3 } & $\mathbf{A}$ & $\mathbf{B}$ & & \\
\hline Deficiency & $7(14.0 \%)$ & $39(78 \%)$ & $46(46 \%)$ & \\
\hline Insufficiency & $14(28 \%)$ & $7(14 \%)$ & $21(21 \%)$ & \multirow{2}{*}{$<0.01$} \\
\hline Sufficiency & $29(58 \%)$ & $4(8 \%)$ & $33(33 \%)$ & \\
\hline Total & $50(100 \%)$ & $50(100 \%)$ & $100(100 \%)$ & \\
\hline Mean & 31.25 & 12.53 & --- & \\
\hline SD & 10.05 & 9.41 & --- & \\
\hline
\end{tabular}

Table 4. Comparison of cord D3 levels among study groups

\begin{tabular}{|l|c|c|c|c|}
\hline \multirow{2}{*}{ Cord blood D3 levels } & \multicolumn{2}{|c|}{ Group } & \multirow{2}{*}{ Total } & \multirow{2}{*}{ P-value } \\
\cline { 2 - 3 } & A & B & & \\
\hline Deficiency & $11(22 \%)$ & $37(74 \%)$ & $48(48 \%)$ & \\
\hline Insufficiency & $14(28 \%)$ & $8(16 \%)$ & $22(22 \%)$ & \multirow{2}{*}{$<0.01$} \\
\hline Sufficiency & $25(50 \%)$ & $5(10 \%)$ & $30(30 \%)$ & \\
\hline Total & $50(100 \%)$ & $50(100 \%)$ & $100(100 \%)$ & \\
\cline { 1 - 3 } Mean & 29.51 & 13.88 & $<0.01$ & \\
\hline SD & 10.03 & 9.84 & & \\
\hline
\end{tabular}

Table 5. Association of birth weight with D3 levels

\begin{tabular}{|c|c|c|c|}
\hline \multirow{2}{*}{ D3 level at labour } & \multicolumn{2}{|c|}{ Birth weight } & \multirow{2}{*}{ Total } \\
\hline & $<2.5 \mathrm{Kg}$ & $>2.5 \mathrm{Kg}$ & \\
\hline Deficiency & $12(26.1 \%)$ & $34(73.9 \%)$ & $46(100 \%)$ \\
\hline Insufficiency & $4(19 \%)$ & $17(81 \%)$ & $21(100 \%)$ \\
\hline Sufficiency & $1(3 \%)$ & $32(97 \%)$ & $33(100 \%)$ \\
\hline Total & $17(17 \%)$ & $83(83 \%)$ & $100(100 \%)$ \\
\hline P-value & & & \\
\hline
\end{tabular}

Table 6. Association of mode of delivery with D3 levels

\begin{tabular}{|l|c|c|c|}
\hline \multirow{2}{*}{ D3 levels at labour } & \multicolumn{2}{|c|}{ Mode of delivery (n=100) } & \multirow{2}{*}{ Total } \\
\cline { 2 - 3 } & FTND & LSCS & \\
\hline Deficiency & $29(63 \%)$ & $17(37 \%)$ & $46(100 \%)$ \\
\hline Insufficiency & $14(66.7 \%)$ & $7(33.3 \%)$ & $21(100 \%)$ \\
\hline Sufficiency & $19(57.6 \%)$ & $14(42.4 \%)$ & $33(100 \%)$ \\
\hline Total & $62(62 \%)$ & $38(38 \%)$ & $100(100 \%)$ \\
\hline P-value & \multicolumn{3}{|c|}{0.783} \\
\hline
\end{tabular}

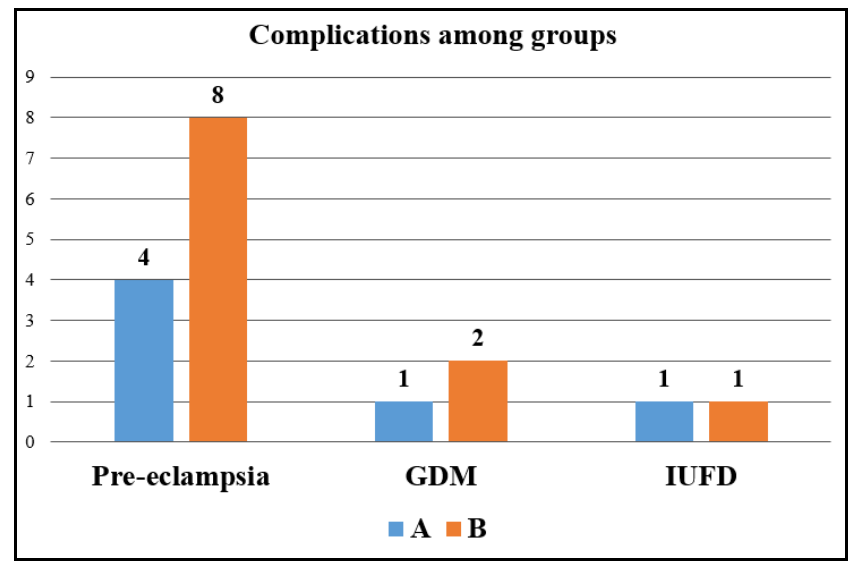

Fig. 1: Comparison of complications among study groups 


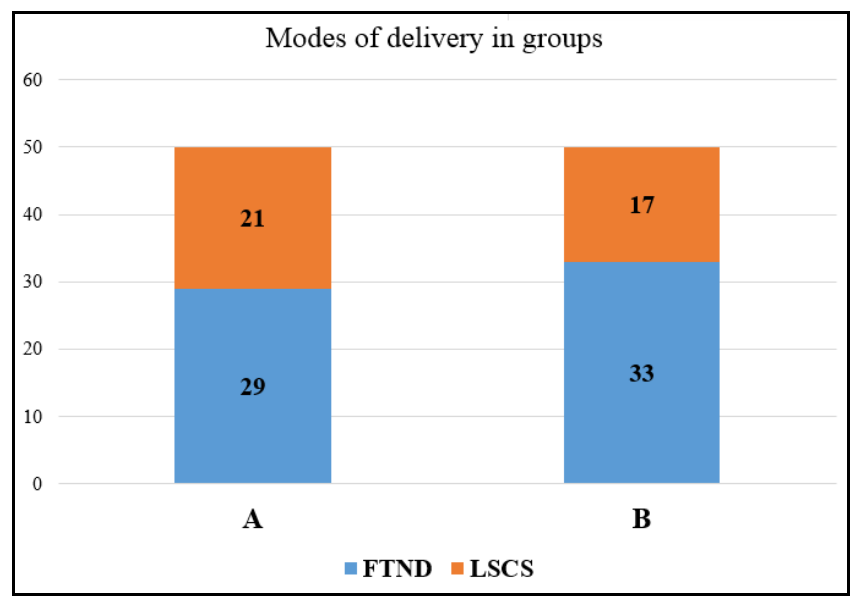

Fig. 2: Comparison of mode of delivery among study groups

\section{Discussion}

Vitamin D is an important hormone in the body which is essential for physiologic processes like calcium absorption, bone development etc. Recently, role of vitamin D plays in the regulation of cell growth, immunity, and cell metabolism has been well understood. The vitamin D deficiency has a greater impact on the development during pregnancy and foetal stage. Complications arising due to vitamin D deficiency despite of it being a preventable condition makes it a public health concern. In the present study, we evaluated the prevalence of vitamin D deficiency in pregnancy and new borns and also assessed the efficacy of current schedule of vitamin D supplimentation.

In the present study, the prevalence of vitamin $\mathrm{D}$ deficiency in mothers was $82 \%$ while in neonates it was observed as $74 \%$. Similarly in a study by Emadi et al ${ }^{6}$ Vitamin D deficiency/ Insufficiency was seen in $89.9 \%$ mothers and $81.2 \%$ neonates while Abbasian et al. ${ }^{7}$ observed vitamin D insufficiency in more than half of the mothers and neonates, $(60.2 \%$ of mothers and $48.9 \%$ of neonates). In a study from China, Jing Wang et al. reported $57.1 \%$ of pregnant women and $44.2 \%$ showed a deficiency, and $97.4 \%$ of women and $96.1 \%$ of neonates showed vitamin D insufficiency. ${ }^{8}$ High prevalence of vitamin $\mathrm{D}$ deficiency has been reported in women in different countries which is in line with the findings of our study.

In Northern India, New Zealand and the Netherlands, vitamin D deficiency has been found as $72 \%, 61 \%$, and $60-84 \%$ respectively among of pregnant women and in northern Canada, $46 \%$ of mothers and $36 \%$ of their babies, are vitamin D deficient. ${ }^{9,10}$

Role of Vitamin D Supplementation: Various studies concluded that the daily use of optimal dosages of vitamin D supplements would help to eliminate vitamin $\mathrm{D}$ insufficiency without apparent toxicity in pregnant women and their infants (11-13). In the present study, after supplementation of $400 \mathrm{IU}$ vitamin D among the study subjects along with calcium $1000 \mathrm{mg}$ daily, the prevalence of vitamin D deficiency reduced from $82 \%$ to $14 \%$ but sufficient levels were achieved in only $58 \%$. Hypercalcemia, which is considered as the most worrying toxicity, occurs with vitamin D levels of more than 80 or $100 \mathrm{ng} / \mathrm{ml}$; and in our study, no one reached this level throughout pregnancy and in newborns with normal levels of calcium in spite of supplementation. Emadi et al. ${ }^{14}$ in their study used a 50,000 IU dose, which demonstrated a significant improvement with no toxicity. Similar results were observed by other author`s as well. . $^{14,15}$

Effect of Vitamin D Deficiency on Mode of Delivery: The relation between vitamin D deficiency and increased rate of cesarean section has already been studied by various authors. But in our study, we did not found statistical significance between vitamin D deficiency and rate of cesarean section. The rate of Caesarean section observed among group $\mathrm{A}$ and $\mathrm{B}$ with the rate of $42 \%$ and $34 \%$ respectively (p-value: 0.54 ).

Effect on Vitamin D deficiency on Pregnancy Complications: In our study preeclampsia was seen in $16 \%$ cases in group B as compared to $8 \%$ in group A, but the difference was not significant with a p-value of 0.36 . Other complications like GDM and IUFD was comparable between the two groups with a p-value of $>0.05$.

Effect on Vitamin D Deficiency on Birth Weight: The importance of vitamin D and normal physical development has been already studied. Several studies have reported an association between infant size, weight and vitamin D status (16). The reduced concentration of vitamin $\mathrm{D}$ in mothers during late pregnancy is associated with the reduced bone mineral content in their children. ${ }^{17}$ In present study, birth weight was observed to be associated with vitamin D levels. Birth weight of $<2.5 \mathrm{Kg}$ was seen in only $3 \%$ babies born to Vitamin D sufficient mothers as compared to $19 \%$ and $26.1 \%$ in mothers with insufficient and deficient levels $(p<0.05)$. Our study demonstrated that low vitamin $\mathrm{D}$ level is very common in pregnant mothers. Routine supplementation of pregnant mothers with daily $400 \mathrm{IU}$ vitamin D with $1000 \mathrm{mg}$ calcium 
resulted in improvement of vitamin D levels but expected results have not been achieved. Newborn's vitamin D levels also correlate with the vitamin D level of their mothers which exposes the babies born to vitamin-deficient mothers to a spectrum of associated complications. Other factors affecting vitamin D levels in pregnant females like eating pattern, compliance with prescribed drugs and sunlight exposure should also studied.

\section{Conclusion}

According to our findings, more than three fourth of the mothers and their neonates had some degrees of vitamin $\mathrm{D}$ deficiency. With regard to the important effects of this vitamin D deficiency on the health of both pregnant women and their neonates, we recommend evaluation of the status of vitamin $\mathrm{D}$ in all pregnant women along with D3 supplementation. Routine supplementation of pregnant mothers with 400IU vitamin D with calcium $1000 \mathrm{mg}$ daily resulted in significant improvement of vitamin D levels in the study group, but sufficient levels were reached in just over half of the females. We thus propose further research on the daily dosage recommendations along with other factors affecting vitamin D levels in pregnant females like the eating pattern, compliance with prescribed drugs and sunlight exposure.

\section{References}

1. Urrutia RP, Thorp JM. Vitamin D in pregnancy: current concepts. Curr Opin Obstet Gynecol. [Internet]. 2012 Mar [cited 2018 Jan 20];24(2):57-64. Available from: http://www.ncbi.nlm.nih.gov/pubmed/22327734

2. Mithal A, Kalra S. Vitamin D supplementation in pregnancy. Indian J Endocrinol Metab. [Internet]. 2014 Sep [cited 2018 Jan 20];18(5):593-6. Available from: http://www.ncbi.nlm.nih.gov/pubmed/25285272

3. Thorne-Lyman A, Fawzi WW. Vitamin D during pregnancy and maternal, neonatal and infant health outcomes: a systematic review and meta-analysis. Paediatr Perinat Epidemiol. [Internet]. 2012 Jul [cited 2018 Jan 20];26 Suppl 1(0 1):75-90. Available from: http://www.ncbi.nlm.nih.gov/pubmed/22742603

4. Urrutia-Pereira M, Solé D. Deficiência de vitamina D na gravidez e o seu impacto sobre o feto, o recém-nascido e na infância. Rev Paul Pediatr. [Internet]. 2015 Mar [cited 2018 Jan 20];33(1):104-13. Available from: http://www.ncbi.nlm.nih.gov/pubmed/25662013

5. Mulligan ML, Felton SK, Riek AE, Bernal-Mizrachi C. Implications of vitamin D deficiency in pregnancy and lactation. Am J Obstet Gynecol. [Internet]. 2010 May [cited 2018 Jan 20];202(5):429.e1-9. Available from: http://www.ncbi.nlm.nih.gov/pubmed/19846050

6. Al Emadi S, Hammoudeh M. Vitamin D study in pregnant women and their babies. Qatar medical journal. 2013;1:7.

7. Abbasian M, Chaman R, Amiri M, Ajami ME, Jafari-Koshki T, Rohani H, Taghavi-Shahri SM, Sadeghi E, Raei M. Vitamin D Deficiency in Pregnant Women and Their Neonates. Global journal of health science. 2016, Jan 4;8(9):83.

8. Wang J, Yang F, Mao M, Liu D-H, Yang H-M, Yang S-F. High prevalence of vitamin $\mathrm{D}$ and Calcium deficiency among pregnant women and their newborns in Chengdu, China. World J Pediatr. 2010;6(3):265-267.

9. Judkins, A., \& Eagleton, C. (2005). Vitamin D deficiency in pregnant New Zealand women. The New Zealand medical journal. 2005;119(1241): 2144-2144.

10. Sachan, A., Gupta, R., Das, V., Agarwal, A., Awasthi, P. K., \& Bhatia, V. (2005). High prevalence of vitamin D deficiency among pregnant women and their newborns in northern India. The American journal of clinical nutrition. 2005;81(5):1060-1064

11. Saadi HF, Dawodu A, Afandi BO, Zayed R, Benedict S, Nagelkerke N. Efficacy of daily and monthly high-dose calciferol in vitamin D-deficient nulliparous and lactating women. Am J Clin Nutr. 2007;85:1565-1571.

12. Hollis BW, Wagner CL. Vitamin D requirements during lactation: high-dose maternal supplementation as therapy to prevent hypovitaminosis D for both the mother and the nursing infant. Am J Clin Nutr. 2004;80:1752S-1758S.

13. Wagner CL, Hulsey TC, Fanning D, Ebeling M, Hollis BW. High dose vitamin D3 supplementation in a cohort of breastfeeding mothers and their infants: a six month followup pilot study. Breastfeed Med. 2006;2:59-70.

14. Mahdy SM, Al-Emadi SA, Khanjar IA, Hammoudeh MM, Sarakbi HA, Siam A-RM, Abdelrahman MO. Vitamin D status in health care professionals in Qatar. Saudi Med J. 2010;31:74-77.

15. Siam AR, Hammoudeh M, Khanjer I, Bener A, Sarakbi H, Mehdi S. Vitamin D deficiency in rheumatology clinic practice in Qatar. QMJ. 2006;15:49-51.

16. Mannion CA, Gray-Donald K, Koski KG. Association of low intake of milk and vitamin $\mathrm{D}$ during pregnancy with decreased birth weight. CMAJ. 2006;174:1273-1277.

17. Javid MK, Crozier SR, Harvey NC, Gale CR, Dennison EM, Boucher BJ, Arden NK, Godfrey KM, Cooper C, Princess Anne Hospital Study Group Maternal vitamin D status during pregnancy and childhood bone mass at age 9 years: a longitudinal study. Lancet. 2006;367:36-43.

18. McGrath J. Dose imprinting with low prenatal vitamin D contribute to the risk of various adult disorders? Med Hypotheses. 2001;56:367-371.

19. Barker DJP. Mothers, Babies and Health in Later Life. 2nd ed. Edinburgh, UK: Churchill Livingstone; 1998.

How to cite this article: Patil $S$, Tripathi $S$, Shah S. Evaluation of effect of vitamin D supplementation on vitamin D levels and pregnancy outcome. Ind $\mathbf{J}$ Obstet Gynecol Res. 2018;5(3):344-348. 